\title{
The State of Healthcare Disaster Plans in New Zealand and the Sultanate of Oman: An International Comparative Analysis
}

\author{
Sultan Al-Shaqsi, ${ }^{1}$ Robin Gauld, ${ }^{2}$ David McBride, ${ }^{2}$ \\ Ammar Al-Kashmiri, ${ }^{3}$ and Abdullah Al-Harthy ${ }^{4}$ \\ ${ }^{1}$ Dunedin Hospital, Southern District Health Board, Dunedin School of Medicine, P.O. Box 913, Dunedin 9016, New Zealand \\ ${ }^{2}$ Department of Preventive and Social Medicine, Dunedin School of Medicine, P.O. Box 913, Dunedin 9016, New Zealand \\ ${ }^{3}$ Khoula Hospital, Muscat, Oman \\ ${ }^{4}$ Sultan Qaboos University Hospital, Muscat, Oman
}

Correspondence should be addressed to Sultan Al-Shaqsi; drsultanalshaqsi@gmail.com

Received 2 April 2014; Accepted 5 June 2014; Published 22 June 2014

Academic Editor: Frank Hildebrand

Copyright (C) 2014 Sultan Al-Shaqsi et al. This is an open access article distributed under the Creative Commons Attribution License, which permits unrestricted use, distribution, and reproduction in any medium, provided the original work is properly cited.

\begin{abstract}
Aim. The aim of this study was to carry out an audit of healthcare plans in New Zealand and Oman. Methods. The study utilizes a deductive content analysis method. Written plans from New Zealand District Health Boards (DHBs) and the Omani secondary and tertiary hospitals were analyzed. A checklist was used to score the plans against twelve elements which are command and control, hazard analysis, surge capability, communication, standard operating procedures (SOPs), life-line backups, public and media, training, welfare, coordination, and recovery. Results. There were 14 plans from New Zealand and 7 plans from Oman analysed. The overall coverage of New Zealand plans was $67.5 \%$ compared to $53.3 \%$ in Oman. Plans from both countries scored similarly in "command and control," "hazard analysis," "surge," and "communication" elements. Omani plans scored lower than those of New Zealand in "media and the publicv" "training," "coordination," and "recovery." Both countries scored very low in addressing the welfare of responders. Conclusion. This study highlighted the value of health emergency plans in New Zealand as reflected by the high score of DHBs' coordination. Therefore, a similar approach in Oman will enhance emergency preparedness. Responders' welfare is an issue that needs to be addressed by emergency preparedness plans in both countries.
\end{abstract}

\section{Introduction}

Disasters are unique situations that require advanced planning in order to anticipate their effects and develop countermeasures to mitigate hazards, reduce risks, respond to emergencies, and recover from such events [1]. Disasters are situations of chaos and the quicker the situation is brought under control the better the outcome will be [2]. In contrast, failure to institute control due to weak planning leads to protracted chaos and worse outcomes [3]. Effective planning reduces guesswork during a disaster response. The success and failure of a disaster response are determined by the level of planning of the affected community.

Disaster planning is a systematic process that has four main components: identifying hazards, mitigating risks, preparing and responding to emergencies, and, finally, recovery and development [3]. All components of the planning process have to be documented and recorded for evaluation and future reference. Documentation of the disaster planning process leads to the formulation of disaster plans. Moore defined disaster plans as follows:

"A formal document that (1) assigns roles and responsibilities to individuals and organizations for carrying specific tasks during an emergency; (2) clarifies lines of authority and organizational responsibilities, including how tasks will be coordinated; (3) describes how people and property will be protected; (4) identifies personnel, supplies, facilities and other resources available within or to 
a jurisdiction during response and recovery activities and (5) identifies steps to improve mitigation during response and recovery operations" [4].

Healthcare providers in New Zealand and the Sultanate of Oman are required by national regulations to develop and maintain health preparedness plans. These plans are to encompass the components of disaster planning such as the four Rs (reduction, readiness, response, and recovery) phases [5]. The plans in New Zealand have to meet the Health and Disability Standards (2008) and the plans must reflect the overall national emergency management system [5]. In Oman, the National Committee for Civil Defense is currently developing the first national standards for regional health emergency plans. Disasters covered by healthcare plans are variable and include internal and external potential risks. Internal risks include situations in which the internal structure of the healthcare system is the cause for the disaster such as a collapse of a hospital, failure of power supply, or a staff strike. External risks include earthquakes, tsunamis, and wars. The current healthcare plans from New Zealand and Oman have not been subjected to evaluation.

This study aims to audit the coverage of disaster plans in terms of describing and addressing the main components of the disaster planning process. It is important to appreciate that the goal of such an evaluation is not to show the deficits of emergency plans in both countries; rather it aims to find areas for improvement. Comparative analysis of disaster preparedness across countries shows how healthcare systems adapt to local circumstances and emphasizes the importance of emergency planning internationally.

\section{Methods}

The study consisted of all the responsible authorities in New Zealand (21 DHBs) and Oman (13 hospitals).

The assessment framework was adapted from international emergency plan checklists. The checklists included the World Health Organization Hospital Emergency Response Checklist; the Mass Casualty Disaster Plan Checklist from the Centre for the Study of Bioterrorism and Emerging Infections; and the United States Joint Commission on Accreditation of Healthcare Organizations (JCAHO) Standards for Emergency Management [6-8]. These checklists have been extensively used to audit emergency plans worldwide. The checklist used in this project included twelve generic domains of strategic emergency preparedness which are command and control, hazard analysis, resources and surge capability, communication and logistics, emergency response standard operating procedures (SOPs), life-line backups, public and media, training, security, welfare, coordination, and recovery. Each one of these domains has several specifics. The full checklist has 60 different specifics. The checklist was assessed by five emergency planning experts in New Zealand and Oman for relevance and comprehensiveness.

New Zealand DHB-level current and up-to-date strategic emergency preparedness plans were obtained by contacting all emergency planners in 2009. Fourteen (66.7\%) of the 21 $\mathrm{DHBs}$, at the time, provided hard or electronic copies of their plans. A further public domain search using internet and personal contacts failed to obtain any further plans from nonresponding DHBs.

Similarly, emergency plans of all secondary and tertiary hospitals in Oman were collected in 2009. Primary hospitals were excluded as strategic emergency planning usually occurs at secondary and tertiary level facilities. Seven hospitals $(53.8 \%)$ provided written emergency plans out of possible 13 hospitals in Oman. An internet search and personal contact with clinicians did not locate any further plans.

In this study a deductive approach was utilized given that the aim of the study was to assess the existence of critical elements of emergency preparedness as described by the overall framework of written emergency plans [3].

A content analysis process was used firstly to ascertain the coverage of emergency preparedness elements within plans and secondly to score them according to whether or not they had addressed the specifics of the 12 domains. A value of "one" was given if the specific existed and is described in the plan and "zero" if the specific is not described. The aggregate score was calculated for each plan in all the 12 domains. The national score in each domain is the aggregate of individual plans divided by the number of plans analyzed in each country. All plans were independently scored by the primary researcher and a research assistant. Where disagreement arose on the score, agreement was reached by further review and discussion. A similar method has been used to evaluate the completeness of influenza preparedness plans in Europe [9]. The study did not evaluate the exact quality of the written plans because there are currently no validated systematic scoring systems for quality assessment of written emergency plans.

The results are presented as an average national score of the plans in each of the 12 domains. A percentage of coverage in each of the twelve areas of emergency preparedness between New Zealand and Oman was also calculated from simple division of mean score by the maximum points in each domain.

The Statistical Package for Social Sciences (SPSS) software (SPSS Statistics 12.1, for Windows, New York) will be utilized in the data analysis. In order to assess the significance of differences in the variables, a series of Chi-Square tests and the Fisher exact tests will be used where appropriate. The study has been approved by the New Zealand Multiregion Ethics Committee and the Omani Ministry of Health.

\section{Results}

There were 14 plans from New Zealand included in this analysis out of the 21 DHBs (66.7\%). There were 1056 pages of New Zealand emergency planning material reviewed. In Oman there were seven plans out of a potential 13 plans from the secondary and tertiary hospitals (53.8\%). There were 677 pages of Omani emergency planning material reviewed.

Figure 1 shows the percentage of the national mean scores ( \pm standard deviation) of New Zealand and Omani emergency preparedness plans in 12 strategic emergency preparedness areas. The overall national mean score of the 


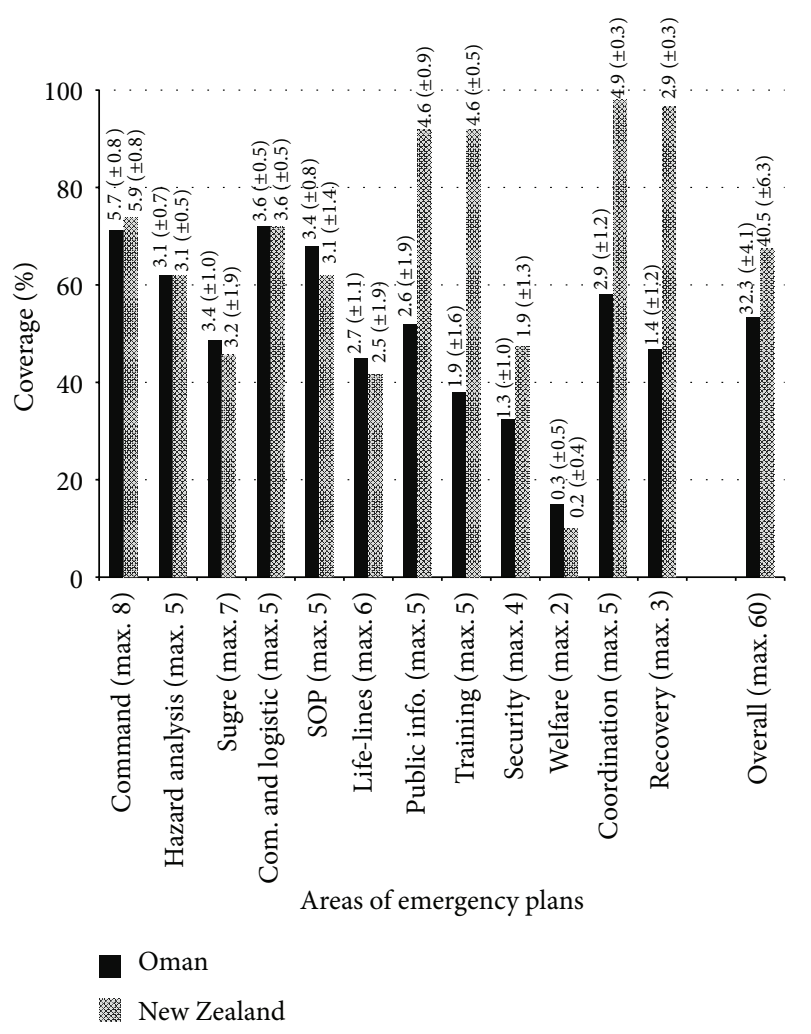

FiguRe 1: Percentage of coverage of emergency preparedness elements in written plans in New Zealand and Oman.

coverage of New Zealand plans was $40.5( \pm 6.3)$ and the percentage was $67.5 \%$ of the maximum possible score (i.e., 60). On the other hand, the Omani overall mean score for coverage of emergency preparedness elements was 32.3 $( \pm 4.1)$, which is $53.3 \%$. Plans from both countries were similar in addressing the "command and control" domain of emergency response $(73.8 \%$ for New Zealand versus $71.3 \%$ for Oman). Alternative arrangements for command and control, such as situations where the command post is destroyed in an emergency, are the least described specific in this domain.

Plans in both countries scored $62 \%$ in the hazard analysis category. However, there was little emphasis on internal hazards such as industrial action by staff strike, disease outbreak in the hospital, and electricity failure. Fire hazard was the only internal hazard that was frequently addressed by plans in New Zealand and Oman. Furthermore, there was no plan that addressed the concept of syndromic surveillance of patient flow and presentations. This concept means continuous monitoring of patient presentations to healthcare services in order to identify clusters of patients that could indicate an early wave of a pandemic [10]. The plans otherwise scored well for external hazard analysis.

The plans in both countries scored less than $50 \%$ of the maximum score for surge capability and resource management (New Zealand: 45.7\%, Oman: 48.6\%). Only a few plans appreciated the value of keeping an updated record of available resources that can be utilised during a mass emergency response. Almost all plans failed to describe a process of enhancing surge capability during a mass emergency event.
The majority of plans used generic and vague comments such as "request resources from the Ministry of Health."

In terms of communication and logistics, plans from both countries scored equally at $72 \%$ of the maximum score. Areas such as establishing a cascade of communication when calling extra healthcare providers are not addressed. Furthermore, emergency plans relying heavily on telephone communications and backup systems such as "runners" were not described.

Omani plans scored an average of $68 \%$ of the maximum score in stating their standard operating procedures (SOPs) compared to New Zealand plans, which scored 62\%. There is a potential for improvement in terms of setting broad guidelines about SOPs such as patient flow, patient tracking systems, and entry and egress to emergency departments. Decontamination of victims prior to definitive healthcare appeared to be an issue that plans underappreciated in both countries.

Emergency plans in New Zealand and Oman scored $41.7 \%$ and $45 \%$ of the maximum score, respectively, in addressing the issue of life-line utilities such as water, food, shelter, sanitation, and power during a mass emergency response. Few plans explicitly discussed how to utilize volunteers and deal with donation of goods and services.

The Omani plans reviewed in this analysis scored significantly lower than their New Zealand counterpart plans in terms of describing a process for dealing with the public and the media during a mass emergency response (52\% versus $92 \%)$. 
The modalities of staff training used and their frequency of occurrence were explicitly addressed in New Zealand plans compared to plans from Oman (92\% versus 38\%). However, the issue of welfare of staff during and after a mass emergency response received little attention in both countries with plans scoring $15 \%$ and $10 \%$ in Oman and New Zealand, respectively. Moreover, security issues and process for healthcare facility lockdown scored $32.5 \%$ and $47.5 \%$ in the Omani and New Zealand plans.

Coordination and collaboration were comprehensively discussed in New Zealand emergency preparedness plans with an aggregate score of $98 \%$. On the other hand, the Omani plans superficially touched on the issue of coordination and collaboration with other agencies during a mass emergency response with an aggregate coverage score of $58 \%$.

Finally, the recovery phase of emergency response was included in almost all New Zealand emergency plans with an aggregate completeness score of $96.7 \%$ compared to $46.7 \%$ in the Omani plans in which the recovery phase did not feature to a significant extent.

\section{Discussion}

The overall national mean scores of 40.5 and $32.5 \%$ of the maximum in New Zealand and Oman mean that there is room for improvement.

The lowest scoring plan was that in ensuring the welfare of staff and first responders, where the scores were around 30$40 \%$ of the maximum. Responding to a disaster is a mentally and physically demanding task for many acute care providers [11]. In New Zealand employees are protected by the Health and Safety Employment Act 1992 in which "employers are required to actively take practical steps to mitigate risk and protect employees" [12]. It is important to appreciate that emergency responders are particularly at risk of postresponse psychological and physical complaints [11]. Identification and control of occupational hazards are essential, and can be simply achieved by providing PPE to responders. Preevent planning should take this into account, and the presence of psychological and physical ill-health should be detected during and after the event. It is an ethical reciprocal duty of the healthcare organization to ensure the welfare of responders and their families in order to maintain high level participation of responders [11]. International studies have found that for most emergency responders the wellbeing of themselves and their families is a priority that has to be addressed and should be explicitly reflected in emergency plans [13].

Security is another important domain that requires more attention in New Zealand and Omani strategic emergency planning. This is to ensure the safety of responders and victims alike. Proper security provides a working environment for responders to provide critical services without interference from the curious worried well people [14]. It is also essential to communicate to the public that such strict security measures are not to limit their rights to access public facilities but to ensure control of the medical response operations established. The importance of such measures became apparent at St Vincent's hospital in New
York City during the September 11, 2001, terrorist attacks in which the worried well inundated the emergency department and hindered the overall medical response [15]. Therefore, strategic emergency planners in New Zealand and Oman could enhance security planning by adopting the lessons learned from international emergencies.

This study found that plans are only $50 \%$ complete when it comes to planning for ensuring essential services such as food, clean water, power, and sanitation measures during an emergency response. The World Health Organization initiated a project called "Safe Hospitals" in which functional failure, such as not maintaining clean water sources for victims and responders, is the most common reason for hospital dysfunction during a disaster response [16]. It is very likely that the public supply of such essential resources will be disrupted and therefore hospitals and healthcare planners have to be vigilant and plan ahead for such possibilities by developing contingency plans to self-sustain for at least 72 hours until external help can be called in [17]. Lessons from New Zealand's Canterbury earthquakes showed the value of being prepared to sustain long-term outages of life-line utilities such as power and water [18]. During the event, extra generators maintained emergency healthcare services at Christchurch Hospital despite the outage of main power supplies. On the other hand, Cyclone Gonu is an Omani example in which failure to provide clean water and a sustained source of food for hospitals contributed to a dysfunctional healthcare response in some hospitals $[19,20]$. For instance, Sur Hospital (a regional secondary hospital) had no clean water supply for days and healthcare staff faced a difficult time trying to source-clean water from local providers. Such examples highlight the need for preparedness of core life utilities.

The coverage of disaster healthcare plans in New Zealand and Oman for strategic emergency preparedness elements is variable. This may be a reflection of the local capability of DHBs and hospitals to conduct a proper emergency planning. The variability in emergency planning exists at a global level. An international survey by the World Health Organization of 60 countries around the world found that $89 \%$ of countries have health-specific emergency plans [21]. This observation was regionally variable; for instance, $40 \%$ of countries in the Pan-Americans Health Office to $78 \%$ in middle-eastern countries conduct strategic emergency planning [21].

Some of the between-countries differences may be due to the national health disaster plans developed in New Zealand. This is clearly evident under the "coordination and collaboration" domain in which plans in this study have $98 \%$ coverage and to a lesser degree under "command and control."

This study showed that there is a clear difference in recovery plans coverage between New Zealand and Oman (96.7\% versus $46.7 \%$ ). Mass emergencies do not end by the arrival of the last patient, but rather they tend to have a long lasting effect. Healthcare recovery plans tend to focus on returning healthcare services to their preevent state. The healthcare recovery tends to be narrow. In reality, recovery planning is a complex community-wide process to basically determine the future of the affected community [1]. 
This study found that disaster plans address "hazard analysis" adequately particularly the external natural and man-made hazards. More improvement could be achieved in terms of analyzing internal hazards such as staff strike, hospital-based outbreaks, and fires. With financial pressure on many DHBs in New Zealand and many hospitals in Oman, staff strikes are becoming frequent and are a likely disruption to the provision of healthcare services [22-24].

The New Zealand health emergency plan delineated clearly how to coordinate and collaborate with other emergency responders such as the police, civil defence, and the military as well as how to institute a command and control structure based on the CIMS principles $[5,25]$. This helps DHBs to establish networks and links with other governmental agencies that could play a role during a mass emergency response and promptly establish a chain of command. On the other hand, the lack of a national health-specific emergency framework in Oman appears to filter down to hospital level planning where plans differ significantly between hospitals and score relatively low on "coordination and collaboration." The results are consistent with published studies from other countries. Ciraulo and others surveyed hospitals in the United States and found that $26.3 \%$ did not address command and control issues in their emergency planning [26, 27]. Furthermore, a comprehensive survey by Mann and others found that $50 \%$ of the states in the USA have no indication of a structure for command and control in healthcare response [28]. However, such studies differ from the survey presented here in that they did not analyze individual plans; rather they surveyed chief executives and asked them about the issues covered or not covered in their institutions' plans.

National standards and guidelines for mass emergency planning, such as the New Zealand Health and Disability Standards (2008), are useful only if adhered to. The value of such strategic guidelines is clear in the high score of New Zealand plans in areas such as "training" and "public information and media." New Zealand DHBs are obliged to meet such standards when formulating an emergency plan. This study found that not all participating DHBs meet all the standards. It is also paramount for policy makers to provide an incentive for DHBs and hospitals to meet national standards. An example of such an approach is to tie emergency planning to an accreditation process. For instance, the Joint Commission for Accreditation of Health Organizations (JCAHO) in the United States provides clear emergency planning standards that have to be met in order to obtain accreditation points [28]. There is a similar system in New Zealand in which DHBs have to show completeness of plans in order to be funded for emergency planning. However, care must be entertained as such an approach might deter DHBs and hospitals from the planning process per se to focus on drafting a presentable plan for the sake of getting the funds.

\section{Strengths and Limitations}

This study has several strengths and limitations. First, it is the first attempt to systematically review and evaluate strategic healthcare emergency preparedness plans in New Zealand and Oman. Second, the emergency plans analyzed in this study are representative samples of plans in both countries. However, it is possible that nonresponding agencies might have different levels of planning and preparedness and therefore are less inclined to share their plans. If this is the case, the results presented here will overestimate the coverage and completeness of strategic emergency plans.

Third, emergency planning is a process and a moving target. Therefore, this study is only a snapshot in the 20092010 period and the plans analysed here might well have changed. There have been several events in both countries (e.g., Canterbury earthquakes and Cyclone Phet) that were catalysts for plan reviews. Hence, the areas for improvement addressed by this study might have already been incorporated in the current hospital preparedness plan in New Zealand and Oman. Multiple studies have reported this particular limitation of mass emergency preparedness surveys [26, 29].

Fourth, it is critical to appreciate that plans are only a written document and might not reflect the actual planning process well. Therefore, the coverage and completeness of plans are only an indicator for strategic healthcare emergency preparedness. The preparedness of hospitals to deal with mass emergencies, which can be enhanced by a robust plan, can also be influenced by multiple known and unknown factors such as the nature and circumstances of the mass emergency. The completeness and coverage of the plans could simply reflect the attention to drafting the written document rather than a real preparedness effort. A study by Mounier-Jack and Coker analyzed influenza pandemic plans from several European countries and speculated that a limitation in their study is that written plans can only be considered a proxy for actual planning [9]. Furthermore, in this study DHBs and hospitals might have other emergency plans that were not shared with the authors and that might have addressed operational emergency preparedness issues separately. Therefore, such plans would not factor in this analysis. In such cases, the results presented here would be an underestimate of the coverage of disaster plans. Nevertheless, emergency planners were requested to share all their plans.

Finally, even though the study utilizes objective checklists used widely in emergency preparedness, the scoring system can still be subjective and interpretive. Plans are open to interpretation and scoring is a subjective exercise. However, having two researchers independently scoring the same plan helps to objectify the plan analysis. An associated limitation is that this study did not address the quality of the plans and, instead, focused on the existence of essential emergency preparedness elements in the current written plans in New Zealand and Oman.

\section{Conclusion}

This study offers a method for assessing emergency plans and provides baseline information that will be useful for ongoing planning efforts in New Zealand and Oman as well as for policy makers and researchers in other countries to compare performances with. The study highlighted the value of having a national health emergency plan in New Zealand as 
reflected by the high scores of DHB emergency plans in areas such as coordination and collaboration. Therefore, a similar approach in Oman will assist in conducting comprehensive strategic emergency preparedness planning. A national plan will also streamline relationships and networks with other emergency responders such as the civil defense and the police.

Responders' welfare is an issue that needs to be clearly addressed by strategic emergency preparedness plans in New Zealand and Oman. This study reiterated the concerns of emergency planners about the lack of current measures to look after their "own warriors," while security issues during mass emergency responses are yet to be explicitly covered by emergency plans in both countries. Private security companies have more experience and expertise in such issues than healthcare systems. Therefore, incorporation of the private sector in future studies of health system disaster planning could be important for addressing such issues. Recovery planning and surge capability are also areas that require further development and guidance in terms of strategic emergency preparedness planning in New Zealand and Oman. Disaster planning will continue to be a national priority for healthcare services in New Zealand and the Sultanate of Oman.

\section{Conflict of Interests}

The authors declare that there is no conflict of interests regarding the publishing of this paper.

\section{Authors' Contribution}

Sultan Al-Shaqsi designed and conducted the study and wrote the paper. All others supervised, contributed to, and reviewed the paper.

\section{References}

[1] R. W. Perry and M. K. Lindell, "Preparedness for emergency response: guidelines for the emergency planning process," Disasters, vol. 27, no. 4, pp. 336-350, 2003.

[2] J. F. Waeckerle, "Disaster planning and response," The New England Journal of Medicine, vol. 324, no. 12, pp. 815-821, 1991.

[3] P. M. Ginter, W. J. Duncan, and M. Abdolrasulnia, "Hospital strategic preparedness planning: the new imperative," Prehospital and Disaster Medicine, vol. 22, no. 6, pp. 529-536, 2007.

[4] S. Moore, A. Mawji, A. Shiell, and T. Noseworthy, "Public health preparedness: a systems-level approach," Journal of Epidemiology \& Community Health, vol. 61, no. 4, pp. 282-286, 2007.

[5] National Health Emergency Plan, Wellington Ministry of Health, 2008.

[6] "Hospital Emergency Response Checklist," World Health Organization, Copenhagen, Denmark, 2011.

[7] Association for Professionals in Infection Control Epidemiology, Mass Casualty Disaster Plan Checklist: A Template for Healthcare Facilities, Association for Professionals in Infection Control Epidemiology, Center for the Study of Bioterrorism Emerging Infection, Washington, DC, USA, 2001.
[8] "Revisions to emergency management standards approved for long term care," Joint Commission Perspectives, vol. 22, no. 6, pp. 5-6, 2002.

[9] S. Mounier-Jack and R. J. Coker, "How prepared is Europe for pandemic influenza? Analysis of national plans," The Lancet, vol. 367, no. 9520, pp. 1405-1411, 2006.

[10] K. J. Henning, "Overview of syndromic surveillance. What is syndromic surveillance," Morbidity Mortality Weekly Report, vol. 53, pp. 11-26, 2004.

[11] D. A. Alexander and S. Klein, "First responders after disasters: a review of stress reactions, at-risk, vulnerability, and resilience factors," Prehospital and Disaster Medicine, vol. 24, no. 2, pp. 8794, 2009.

[12] Health and Safety Employement Act, 1992, http://www.osh .dol.govt.nz/law/hse.shtml.

[13] W. B. Rudman, J. F. Metzl, and R. A. Clarke, Emergency Responders: Drastically Underfunded, Dangerously Unprepared: Report of an Independent Task Force, Council on Foreign Relations Press, New York, NY, USA, 2003.

[14] D. Hogan and J. Burstein, Disaster Medicine, Lippincott Williams \& Wilkins, Philadelphia, Pa, USA, 2007.

[15] L. Kirschenbaum, A. Keene, P. O’Neill, R. Westfal, and M. E. Astiz, "The experience at St. Vincent's Hospital, Manhattan, on September 11, 2001: preparedness, response, and lessons learned," Critical Care Medicine, vol. 33, no. 1, pp. S48-S52, 2005.

[16] "Safe Hospitals Project World Health Organization," 2011, http://www.safehospitals.info.

[17] R. D. Zane, P. Biddinger, L. Ide et al., "Use of "shuttered" hospitals to expand surge capacity," Prehospital and Disaster Medicine, vol. 23, no. 2, pp. 121-127, 2008.

[18] J. R. Stevenson, H. Kachali, Z. Whitman, E. Seville, J. Vargo, and T. Wilson, "Preliminary observations of the impacts the 22 February Christchurch earthquake had on organisations and the economy: a report from the field (22 February-22 March 2011)," Bulletin of the New Zealand Society for Earthquake Engineering, vol. 44, no. 2, pp. 290-298, 2011.

[19] S. Al-Shaqsi, "Care or cry: three years from cyclone gonu. What have we learnt?" Oman Medical Journal, vol. 25, no. 3, pp. 162$167,2010$.

[20] M. Y. Alhinai, “Tropical cyclone Gonu: number of patients and pattern of illnesses in the primary health centers in A'Seeb area, Muscat, Sultanate of Oman," Oman Medical Journal, vol. 26, no. 4, pp. 223-228, 2011.

[21] A. Alwan, Global Assessment of National Health Sector Emergency Preparedness \& Response., World Health Organization, Geneva, Switzerland, 2008.

[22] T. L. Farrow and A. J. O'Brien, "Discourse analysis of newspaper coverage of the 2001/2002 Canterbury, New Zealand mental health nurses' strike," International Journal of Mental Health Nursing, vol. 14, no. 3, pp. 187-195, 2005.

[23] J. Rietveld, "Strike action by senior medical staff in Timaru: how did this come about?" New Zealand Medical Journal, vol. 116, pp. 1170-1171, 2003.

[24] G. Robinson, K. McCann, P. Freeman, and R. Beasley, "The New Zealand national junior doctors' strike: implications for the provision of acute hospital medical services," Clinical Medicine, vol. 8, no. 3, pp. 272-275, 2008.

[25] The Ministry of Civil Defence and Emergency Management, "The New Zealand Coordinated Incident Management System (CIMS)," New Zealand Fire Service Commission, Wellington, New Zealand, 2006. 
[26] D. L. Ciraulo, E. R. Frykberg, D. V. Feliciano et al., "A survey assessment of the level of preparedness for domestic terrorism and mass casualty incidents among Eastern Association for the Surgery of Trauma members," The Journal of Trauma, vol. 56, no. 5, pp. 1033-1039, 2004.

[27] W. Higgins, C. Wainright III, N. Lu, and R. Carrico, "Assessing hospital preparedness using an instrument based on the Mass Casualty Disaster Plan Checklist: results of a statewide survey," American Journal of Infection Control, vol. 32, no. 6, pp. 327-332, 2004.

[28] N. C. Mann, E. MacKenzie, and C. Anderson, "Public health preparedness for mass-casualty events: a 2002 state-by-state assessment," Prehospital and Disaster Medicine, vol. 19, no. 3, pp. 245-255, 2004.

[29] B. Adini, A. Goldberg, D. Laor, R. Cohen, R. Zadok, and Y. BarDayan, "Assessing levels of hospital emergency preparedness," Prehospital and Disaster Medicine, vol. 21, no. 6, pp. 451-457, 2006. 


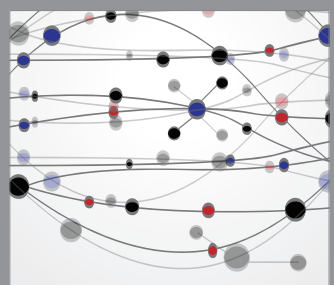

The Scientific World Journal
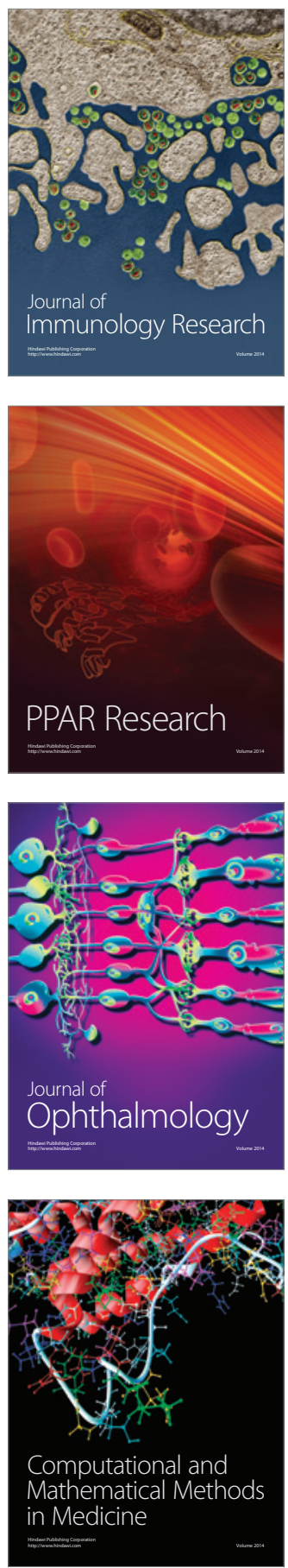

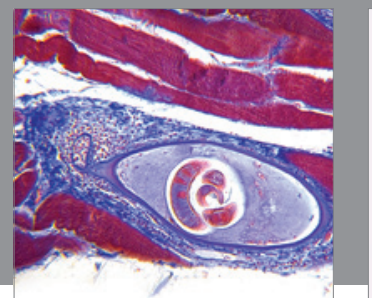

Gastroenterology

Research and Practice
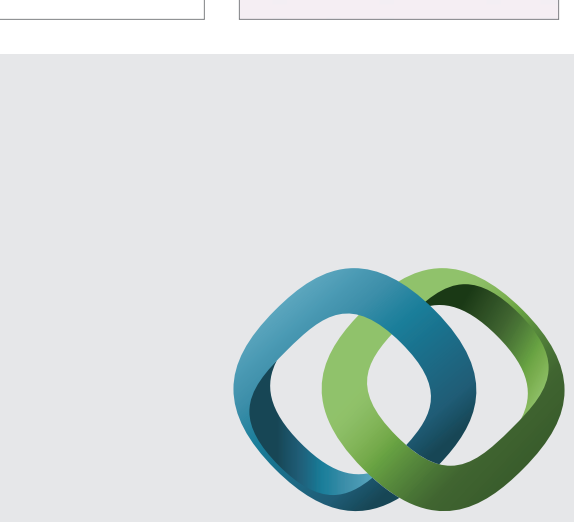

\section{Hindawi}

Submit your manuscripts at

http://www.hindawi.com
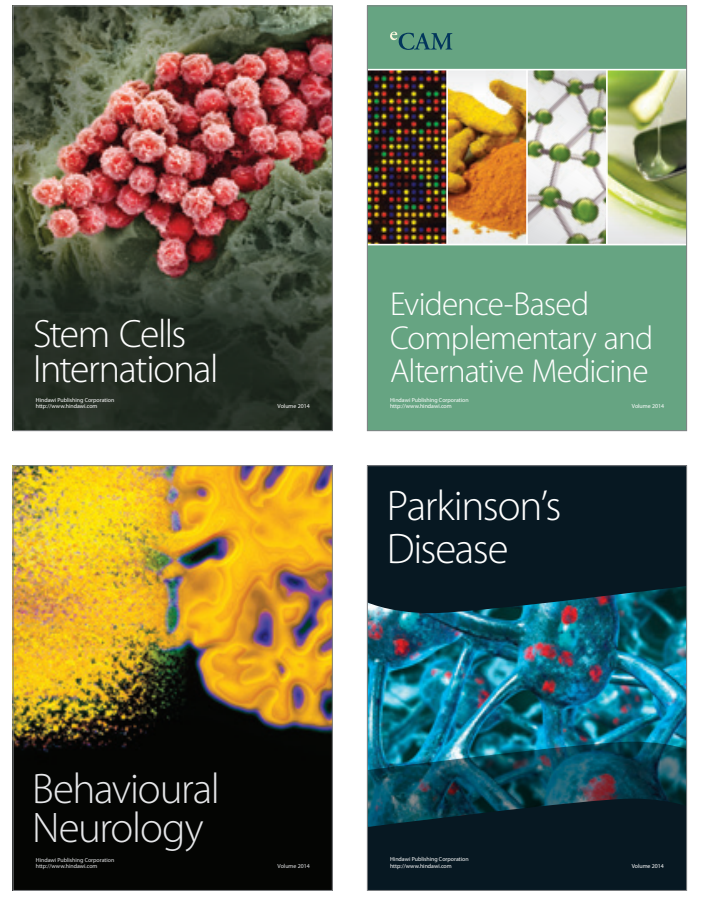
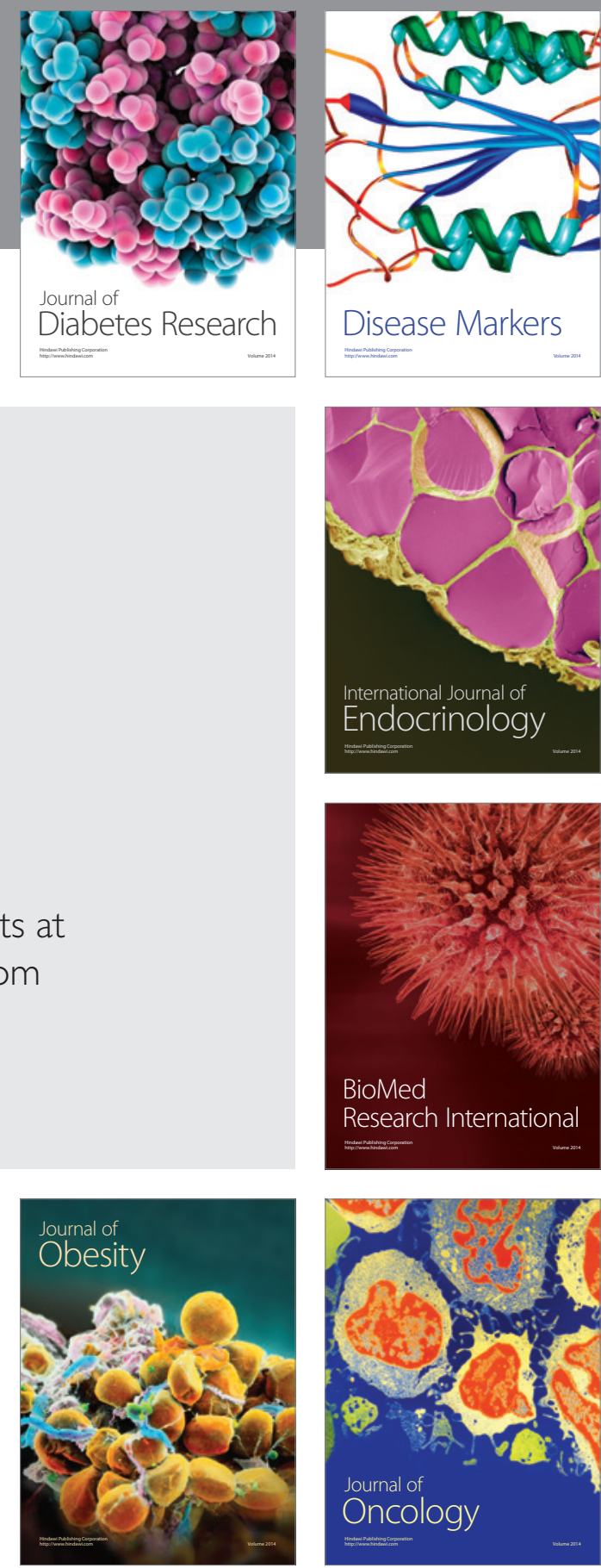

Disease Markers
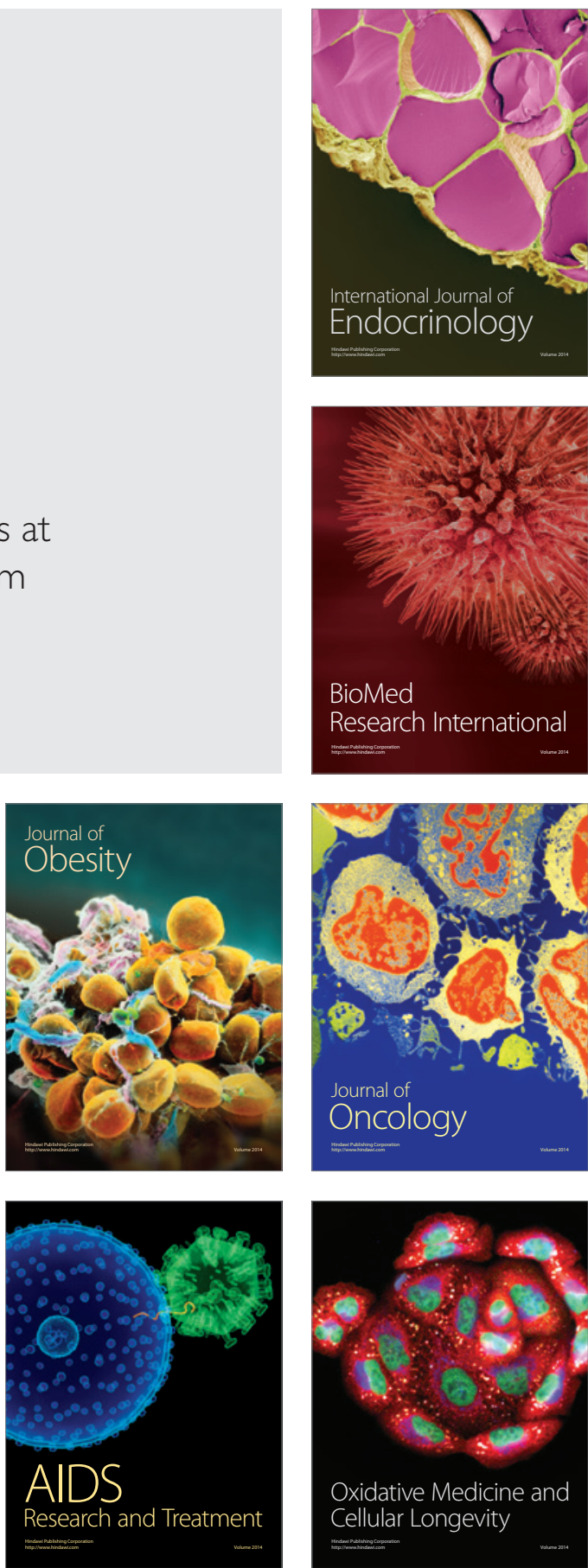